\title{
Measured and modelled trends in European mountain lakes: results of fifteen years of cooperative studies
}

\author{
Aldo MARCHETTO* and Michela ROGORA \\ CNR Institute of Ecosystem Study, L.go Tonolli 50, 28922 Verbania Pallanza, Italy \\ *e-mail corresponding author: a.marchetto@ise.cnr.it
}

\begin{abstract}
Papers included in this Special Issue of the Journal of Limnology present results of long-term ecological research on mountain lakes throughout Europe. Most of these studies were performed over the last 15 years in the framework of some EU-funded projects, namely AL:PE 1 and 2, MOLAR and EMERGE. These projects together considered a high number of remote lakes in different areas or lake districts in Europe. Central to the projects was the idea that mountain lakes, while subject to the same chemical and biological processes controlling lowland lakes, are more sensitive to any input from their surroundings and can be used as earlywarning indicators of atmospheric pollution and climate change. A first section of this special issue deal with the results of long-term monitoring programmes at selected key-sites. A second section focuse on site-specific and regional applications of an acidification model designed to reconstruct and predict long-term changes in the chemistry of mountain lakes.
\end{abstract}

Key-words: air pollution, acidification, climate change, lake districts, EU-projects

\section{INTRODUCTION}

At the end of the ' $80 \mathrm{~s}$, it became clear that mountain areas in Europe were receiving air pollutants coming from the industrialized areas in the lowlands. In June 1989, a workshop was held in Pallanza, Italy, to take stock of the knowledge on the effect of this process on high mountain lakes and to address further research (Johannessen et al. 1990).

After three days of discussion, 51 researchers coming from 14 countries agreed on the concept that high mountain lakes, while subject to the same chemical and biological processes controlling lowland lakes, are more sensitive to any input from their surroundings. The vulnerability of mountain lakes makes them suitable "early response" indicators of changes in atmospheric deposition of air pollutants and in the regional climate. Modelling was identified as an important tool for understanding, monitoring and predicting the effects of these changes on mountain lakes.

The following operational goals were set to address future research on these ecosystems: (i) to identify background levels of pollutants; (ii) to establish reliable acidification models to quantify the present level of acidification and to forecast lake evolution; (iii) to identify tracers for atmospheric pollution; (iv) to set-up a long-term monitoring programme, to investigate an early response of mountain lakes to climatic changes; (v) to encourage comparison studies among lake districts.

The European Commission supported the conclusions of this meeting and funded a number of research projects designed to attain the suggested goals (Tab. 1). This volume reports some of the results of those pro- jects, comparing different lake districts (Fig. 1) and focusing on the results of the long-term monitoring programme and on the application of acidification models to high mountain lakes, which also leads to the identification of background levels of pollutants.

\section{RESEARCH PROJECTS ON MOUNTAIN LAKES}

The first project, "Quantification of the Susceptibility of Alpine Lakes to Acidification" (1988-91) involved four Institute in Italy, Switzerland and Austria. Results showed that atmospheric deposition in the Alps is moderately acid, and can be buffered by the episodic input of Saharan calcareous dust and by the alkalinity produced by watershed processes (calcite and silicate weathering and nitrogen uptake by the vegetation) (Mosello et al. 1993).

A detailed study was performed in the Canton Ticino, which proved to be the area in which Alpine lakes were most affected by acid deposition: a titration model (Henriksen et al. 1990) was used to evaluate recovery scenarios according to different hypotheses of pollutant emission reduction. It was found that a $55 \%$ reduction in the loading of nitrate $\left(\mathrm{NO}_{3}{ }^{-}\right)$and sulphate $\left(\mathrm{SO}_{4}{ }^{2-}\right)$ would result in safe alkalinity values for about $90 \%$ of the lakes. If ammonium $\left(\mathrm{NH}_{4}{ }^{+}\right)$was also included in the loading reduction, all the lakes could be recovered (Boggero et al. 1998). The study of lake sediments revealed the history of some Alpine lakes, showing that $\mathrm{pH}$ decreased in the second half of the $20^{\text {th }}$ century, when a parallel increase in the concentration of spherical carbonaceous particles of industrial origin was also detected for the same period, highlighting the relation between air pollution and lake acidity (Guilizzoni et al. 1996). 
Tab. 1. EU-funded projects on mountain lakes with the number of countries and institutes involved and the number of lakes included.

\begin{tabular}{|c|c|c|c|c|}
\hline Project & Period & Institutes & Countries & Lakes \\
\hline Quantification of the Susceptibility of Alpine Lakes to Acidification & $1988-91$ & 4 & 3 & 413 \\
\hline AL:PE "Acidification of mountain Lakes, Paleolimnology and Ecology" & $1991-93$ & 7 & 4 & 12 \\
\hline AL:PE 2 & $1994-95$ & 17 & 12 & 28 \\
\hline $\begin{array}{l}\text { MOLAR "Measuring and modelling the response of remote mountain lakes ecosystems } \\
\text { to environmental changes: a programme of MOuntain LAke Research" }\end{array}$ & $1995-99$ & 22 & 14 & 33 \\
\hline $\begin{array}{l}\text { EMERGE "European Mountain lake Ecosystems: Regionalisation, diaGnostic and } \\
\text { socio-economic Evaluation" }\end{array}$ & $2000-03$ & 23 & 13 & 300 \\
\hline
\end{tabular}

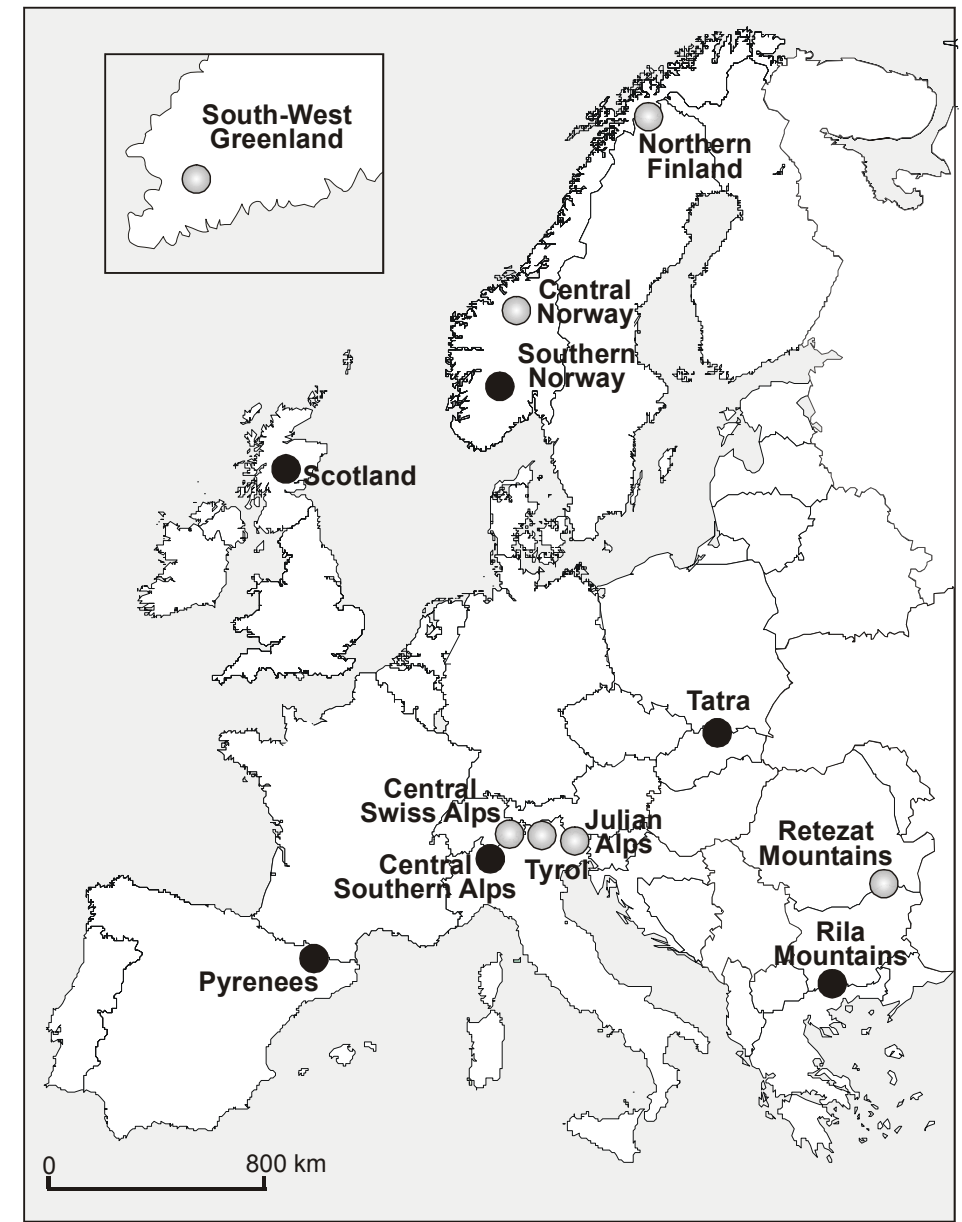

Fig. 1. Lake Districts considered in the EMERGE Programme. Full circles show the location of sites or regions where long term trends (measured or modelled) in mountain lakes were considered in this Special Issue.

The second project, "Acidification of mountain Lakes, Paleolimnology and Ecology: AL:PE" (199195), included 27 lakes (Tab. 1), located in Austria, France, Ireland, Italy, Norway, Portugal, Russia (the Kola Peninsula), Scotland, Slovakia, Slovenia, Spain and the Svalbard Islands. The sites were selected to be above (in the mountains) or beyond (in the arctic regions) the local timberline, and undisturbed by human activity, in both clean and polluted areas of Europe (Wathne 1992).

Acidified lakes were found in the Alps, Southern Norway, the Scottish highlands and Ireland. Sulphate concentration in the lakes followed the pattern of sul- phur (S) oxide emissions in Europe, while nitrogen (N) concentration was very high in the Tatras and in the Alps (Wathne et al. 1993). Benthic diatoms and invertebrate assemblages were clearly related to lake water $\mathrm{pH}$. The impact of acidification was registered through the progressive loss of gastropods, mayflies, stoneflies, caddis flies and crustaceans. Fly-ash coming from industry, trace metals and organic pollutants were found in all lakes in Europe, however remote. In particular, cadmium levels were highest at sites close to industrial areas (Scottish Highlands, Alps and Tatras), while mercury and some organic pollutants, such as DDT derivatives showed high concentrations at sites located at 
higher altitudes (Tyrol, Pyrenees) or latitudes (the Svalbard Islands), both in lake sediment and in fish tissues. The onset of metal contamination was generally dated between 1810 and 1860; carbonaceous particles of industrial origin were found in sediment as old as 190020, peaking in all sites between 1950 and 1980 (Wathne et al. 1990).

The MOLAR project ("Measuring and modelling the response of remote mountain lakes ecosystems to environmental changes: a programme of MOuntain LAke Research", 1995-99) involved 24 institutions and considered 23 remote lakes in different European countries, from the Svalbard Island to the South of Spain (Patrick et al. 1998; Straškrabová et al. 1999). Atmospheric deposition was sampled at 11 sites, representative of different lake districts. Results showed quite high variability, with the highest values of acidity recorded in Central Europe and at some Alpine stations. In the Scandinavian area, a decreasing gradient form south to north was observed, owing to the lower acidic input in the northernmost regions (The MOLAR Water Chemistry Group 1999). The atmospheric loads of $\mathrm{N}$ compounds were high, so that surface water was characterised by high $\mathrm{NO}_{3}{ }^{-}$concentrations, above all in the lakes of the Tatras and the Alps. Lake watersheds were in most cases formed of slightly soluble rocks; as a consequence, most lakes proved to be sensitive to acidification (Psenner et al. 2000). The analysis of long term trends, carried out for a restricted group of lakes, showed an increase of $\mathrm{pH}$ and alkalinity values. This recovery was mostly due to the reduction of acid input from the atmosphere, but the role played in these variations by climatic changes and eventual extreme climatic events should be considered (Mosello et al. 2002).

In the framework of the MOLAR project critical loads for $\mathrm{S}$ and $\mathrm{N}$ compounds were also evaluated. The lowest values, indicating the most sensitive sites, were found for the lakes in the Tatra Mountains and in Norway and also for Lake Paione Superiore, in the Italian Alps (Curtis et al. 2002). The least sensitive sites were located in the Swiss and Austrian Alps. The lake response to acidic input is related to the amount of acid deposition and its exceedance with respect to critical loads: in spite of their high sensitivity, Norwegian lakes received acidic inputs lower than their critical loads because of the low acidity of atmospheric deposition at these sites. The models used to calculate critical loads for the MOLAR sites considered both $\mathrm{N}$ and $\mathrm{S}$ input. The decreasing deposition of $\mathrm{SO}_{4}{ }^{2-}$ observed in different parts of Europe reflected the important role played by $\mathrm{NO}_{3}{ }^{-}$as acidifying anion (Curtis et al. 2002).

Data on fluxes and pathways of ions, metals, radionuclides, persistent organic pollutants and spheroidal carbonaceous particles were collected at selected MOLAR sites. These parameters were measured in atmospheric deposition, lake water, sediment and in some cases (metals, organic pollutants) also in fish. The re- sults were not very different from those obtained at more polluted sites, underlying the outstanding importance of long range transport of airborne pollutants.

Metal concentrations in fish, in particular $\mathrm{Hg}$, were low in all the lakes. Low temperatures, low concentrations of dissolved organic carbon (DOC), high transparency and organic content in sediments are all factors associated with low methylation rates of $\mathrm{Hg}$ in lake water. The same effect derived from the low trophic status and the short food chains which characterise these ecosystems. This also explained the low fish concentrations in fish of PCBs and less volatile organochlorines.

The link between climate variability and ecosystem dynamics was also investigated by modelling meteorological data to produce useful information about air and water temperature and ice cover in high mountain lakes. These models can be built using data from meteorological stations located close to the lake but also using long series of climatic data obtained from more distant locations. This comparison allowed the reconstruction of climatic information for each lake over the last 200 years. To verify the results, they were compared to data obtained from sediment analysis. Climatic changes are well recorded by the content of organic matter in the sediment and by diatom and chironomid assemblage composition. Model validation was confirmed by consistent variations observed for the different sites.

The EMERGE programme (European Mountain lake Ecosystems; Regionalisation, diaGnostic and socio-economic Evaluation, 2000-2003) was carried out by 26 Institutions and involved about 300 lakes all over Europe located above or beyond the local timberline, in 13 areas or Lake districts (Fig. 1). It built upon previous studied of mountain lakes together with new studies and with data from national projects to carry out a comprehensive evaluation of the status of remote mountain lake ecosystems throughout Europe.

One of the major outputs of this project was a suggested typology of mountain lakes that might be useful as a guideline for pan-European analysis and for the implementation of the Water Framework Directive (WFD) at a regional level but within the European context (Kernan \& Catalan 2003). EMERGE contributed to the requirements of the WFD by (i) providing information on the ecological and chemical status of European mountain lakes, (ii) defining reference conditions and divergence from them, (iii) identifying the most appropriate parameters for defining the ecological status of the lakes and (iv) proposing criteria for monitoring lakes within the aims of the Directive (Kernan \& Catalan 2003).

The results obtained from the different work-packages within EMERGE are under evaluation and dataelaboration is still in course. An interesting output from the analysis of the biological data was that there are independent typologies of lake fauna in at least three areas: the Arctic limno-region (Nothern Finland), the Nordic limno-region (Scotland and Norway) and the 
Alpine limno-region (all the mountain ranges below $50^{\circ}$ latitude). Within these three regions, there were no clear sub-divisions into classes. The gradient based on lake Acid Neutralising Capacity (ANC) proved to be the most suitable to establish discontinuities between typologies of lakes (Kernan \& Catalan 2003).

Some of the data collected within EMERGE at selected mountain lakes in the Alps, the Tatras, Scotland and Norway, together with data available from previous projects, are discussed in the first section of this Special Issue, dealing with measured trends. A second section includes modelling papers describing regional or sitespecific applications of the dynamic model MAGIC (Model of Acidification as Groundwater in Catchments; Cosby et al. 2001) to reconstruct acidification history and predict future recovery for mountain lakes. MAGIC simulations were conducted as part of the EMERGE and RECOVER:2010 projects. RECOVER:2010 (20002003) mainly aimed at evaluating the extent of recovery of acidified freshwater in Europe in response to the reduced deposition of acidifying compounds, and at quantifying the dominant lake and catchment processes governing the timing and magnitude of recovery. It did not deal only with mountain lakes but also with lakes, rivers and atmospheric deposition in region heavily (Upland UK, Central Europe, High Tatras) and moderately (Southern Norway, Alps) polluted regions. The main outputs of RECOVER:2010 have been presented in two Special Issues of Hydrology and Earth System Sciences (Jenkins et al. 2001; Ferrier et al. 2003).

\section{LONG-TERM MONITORING AND PALAEOLIMNOLOGICAL DATA}

At the time when high mountain lakes were being systematically monitored, acidification processes had already reached their maximum. Palaeolimnological data show that sensitive European mountain lakes experienced their maximum $\mathrm{pH}$ decrease in the 1960s and '70s (e.g., Jones et al. 1993; Guilizzoni et al. 1996). The coincidence of lake acidification and the deposition in remote lakes of carbonaceous particles of industrial origin with the increase in thermoelectric power production is a clear indication that the long-range transport of air pollutants from industrialized areas to mountain regions was responsible for the decline in lake $\mathrm{pH}$ (Lami et al. 1994; Rose et al. 2002) .

Recognition of the continental scale of the problems relating to acidification and deposition of air pollutants, as well as the requirement for international solutions, prompted the adoption, in 1979, of the Convention on Long Range Transboundary Air Pollution (CLRTAP). The Convention entered into force in 1983 and was subsequently extended by eight specific protocols. The most recent Protocol, for the abatement of acidification, eutrophication and ground-level ozone was adopted in Gothenburg in 1999 (UN-ECE 1999) and sets emission ceilings for 2010 . In the 1980 s, the reduction of S emis- sion led to a substantial decrease in the content of nonmarine $\mathrm{SO}_{4}{ }^{2-}$ in atmospheric deposition. However, an increase in nitrogen oxide $\left(\mathrm{NO}_{\mathrm{x}}\right)$ emission, and then in $\mathrm{NO}_{3}{ }^{-}$deposition, counterbalanced the decrease in $\mathrm{SO}_{4}{ }^{2-}$.

Monitoring data show that in Lochnagar (Scotland), the increase in $\mathrm{NO}_{3}{ }^{-}$deposition completely balanced the decrease in $\mathrm{SO}_{4}{ }^{2-}$, and the lake $\mathrm{pH}$ did not show any trend (Rose et al. 2004). In contrast, in Lake Paione Superiore (Italy), steady $\mathrm{NO}_{3}{ }^{-}$and decreasing $\mathrm{SO}_{4}{ }^{2-}$ deposition led to an improvement in lake $\mathrm{pH}$ and alkalinity (Marchetto et al. 2004). As a consequence, no change in the lake biota was detected in the former, while the improved condition of the latter allowed a partial recovery of the diatom community and the reappearance of some sensitive species in zooplankton and zoobenthos.

The long term monitoring activity carried out on both lakes made it possible to demonstrate the importance of nitrogen dynamics and to identify unexpected patterns, like the strong interaction between climate variability and lake $\mathrm{pH}$. This was first revealed by palaeolimnological studies (Psenner \& Schmidt 1992; Marchetto et al. 1993) and confirmed by long term monitoring in both Lochnagar and Lake Paione Superiore. However, the effect of temperature on lake alkalinity was different in Lochnagar, where it was mainly related to the reduced nitrogen retention in cold years, and in Lake Paione where increased rock weathering in warm years was the most important process. Episodic deposition of Saharan dust also has a significant buffering effect on lake acidity in Alpine lakes, as well as in other mountain areas in Southern Europe, such as the Pyrenees (Camarero \& Catalan 1993)

An important effect of climatic change detected through long term monitoring is the increase of DOC levels in the Scottish site, which is not paralleled by a similar pattern in the Alpine site, but is common to other European remote lakes (Skjelkvåle et al. 2001a, b; Evans \& Monteith 2002).

The availability of coherent data series spanning two decades was very useful for calibrating dynamic models used to infer past lake evolution and to forecast future trends, on the basis of deposition scenarios. The pattern is confused by the occurrence of climatic changes together with the trend in pollution and in recovery, which may be delayed for several years by processes at the catchment scale. Shorter-term monitoring of lakes in areas less affected by the long range transport of air pollutants, like the Rila Mountains (Kalchev et al. 2004), is a valuable help in identifying the processes related to climate change in undisturbed systems.

Monitoring metals in atmospheric deposition and in lake sediment showed that in Lochngar metal fluxes from the catchment to the lake have recently increased, in spite of reduced emissions and deposition. While the process leading to the decoupling between metal deposition to and release from the lake catchment is still not clear, it became important to know whether this pattern 
is exclusive to Lochnagar and Scottish Lochs or if it is widespread throughout European mountain regions.

Further monitoring is recommended to allow us to detect the effects and the efficacy of current strategies in deposition reduction, but should be enlarged to include toxic pollutants, which were shown to be present in remote mountain lakes in most of Europe: among them, metals, persistent organic pollutants and endocrine disruptors have yet be found.

\section{MODELLED TRENDS: RECONSTRUCTION AND PREDICTION OF MOUNTAIN LAKE CHEMISTRY}

Protocols under the CLRTAP were based on the critical load concept, which utilises the understanding of emission transport and deposition at a regional scale coupled with the sensitivity of ecosystems as defined by their calculated critical loads. Critical loads, for both soils and surface-waters, are based on an assumption of steady-state and as a consequence are time invariant (Henriksen \& Posch 2001). In reality, the response of surface water ecosystems to decreasing input of acidity is not immediate but may take from years to decades before becoming evident. This delay emerged clearly from monitoring data which showed that the recovery of acid sensitive ecosystems has been modest, despite the fact that $\mathrm{S}$ deposition in Europe has decreased by $50-60 \%$ in the last two decades. Hence further reductions in the emission of acidifying compounds are necessary to accelerate the recovery processes. The estimate of emission reductions and the predictions of lag times between changes in deposition and recovery require the use of dynamic models (Jenkins et al. 2003).

Several process-oriented dynamic models for acidification of soils and waters have been developed and applied over the past 20 years both to reconstruct and predict water chemistry in response to changes in atmospheric deposition (e.g. Cosby et al. 2001; Posch et al. 2003). These models differ in various aspects (different spatial and temporal scales and different resolution) but are based on similar concepts and represent the same physical and chemical processes.

The MAGIC model (Model of Acidification as Groundwater in Catchments) is a process-oriented biogeochemical model for acidification of soils and surface waters. It has been in use for more than 15 years and extensively tested on catchments in North America (e.g., Cosby et al. 1986) and Europe (e.g., Wright et al. 1994; Jenkins et al. 1997). The original formulation of MAGIC has been refined several times over the years. Refinements regarding Al solubility and organic acids as well the recent inclusion of $\mathrm{N}$ dynamics have resulted in the improved performance of the model in simulating soil and surface water chemistry (Wright et al. 1998; Jenkins \& Cullen 2001). The most recent refinements and expansions have been included in version 7.0 of the model (Cosby et al. 2001).
Recently a pan-European assessment was undertaken within the RECOVER:2010 and EMERGE Projects to predict future water chemistry given standard scenarios of future emissions of $\mathrm{S}$ and $\mathrm{N}$ compounds in Europe (Jenkins et al. 2003). The modelling work was conducted in parallel in different regions of Europe focusing on key-areas where acidification impacts have occurred and site specific and regional data were available. Some results of both regional and site-specific model application were reported in a RECOVER:2010 Special Issue published in 2003 (Ferrier et al. 2003). Here we present results of both site-specific and regional applications of the MAGIC model to selected lake districts in Europe (Fig. 1; Tab. 2).

The aims of these studies were to evaluate the modelled long-term trends in water chemistry of selected mountain lakes, to compare modelled and measured trends where measured data were available and to assess the future response of mountain lakes to reductions in $\mathrm{S}$ and $\mathrm{N}$ deposition agreed under the Gothenburg Protocol (UN-ECE 1999). The model was calibrated at the different sites according to standardised procedures. Time sequences of $\mathrm{S}$ and $\mathrm{N}$ deposition since pre-acidification times (mid-1800s) were based on measured deposition data at sampling sites within the lake areas (e.g. Kopacek et al. 2004) as well as on long-term deposition estimates provided by EMEP through the Lagrangian deposition model. The deposition scenarios for the forecast (2010 and beyond) were calculated for the different areas as described by Schöpp et al. (2003).

The model made a good reconstruction of trends in the major chemical variables at those lakes where longterm data series were available (e.g. Øvre Neådalsvatn, Stavsvatn, Lochnagar, Lake Paione Superiore, Redó). These lakes were flag-ship sites within EMERGE and have been intensively studied in the course of the AL:PE and MOLAR projects. MAGIC was calibrated in detail to these sites using both the data of the target year (usually 2000) and the whole time trends in measured data. This procedure allows more robust calibrations compared to those performed for regional datasets where limited data were available. Lakes in the regional datasets of Norway, Scotland, the Southern Alps and the Tatras were selected from sites for which some data from earlier studies existed, to represent a range in the altitudinal gradient (Helliwell \& Kernan 2004), the chemical characteristics and acid-sensitivity (Rogora 2004; Kopacek et al. 2004) or in biological habitats (Wright \& Cosby 2004)

Central Norway proved to be a reference region for more polluted areas in Europe (Tab. 2). In fact, it receives low levels of acid deposition, and there is a general prediction that all the lakes will recover in the near future. In contrast, Southern Norway, the Central Southern Alps and the Tatra Mountains on the other hand receive from moderate to high loads of acidifying compounds (Tab. 2). Some recovery has been detected in 
Tab. 2. Summary of the regional applications of the MAGIC model to some Lake Districts within the EMERGE Programme.

\begin{tabular}{|c|c|c|c|c|c|c|c|}
\hline District & $\mathrm{n}^{\circ}$ of lakes & Acid deposition & $\begin{array}{l}\text { S deposition } \\
\left(\text { meq } \mathrm{m}^{-2} \mathrm{y}^{-1}\right)\end{array}$ & $\begin{array}{l}\mathrm{N} \text { deposition } \\
\left(\text { meq } \mathrm{m}^{-2} \mathrm{y}^{-1}\right)\end{array}$ & $\begin{array}{l}\text { S deposition } \\
\text { decrease }\end{array}$ & $\begin{array}{l}\text { Forecast under the } \\
\text { Gothenburg Protocol }\end{array}$ & Reference \\
\hline Central Norway & 19 & Low & 12 & 15 & $65 \%$ since 1980 & $\begin{array}{l}<25 \% \text { of the lakes } \\
\text { with ANC }<20 \mu \mathrm{eq}^{-1} \\
\text { in } 2016\end{array}$ & Wright \& Cosby 2004 \\
\hline Southern Norway & 23 & Moderate & 33 & 44 & $65 \%$ since 1980 & $\begin{array}{c}\text { About } 60 \% \text { of the } \\
\text { lakes with ANC }<0 \\
\mu \text { eq } 1^{-1} \text { in } 2016\end{array}$ & Wright \& Cosby 2004 \\
\hline Scottish Highlands & 30 & Moderate & 30 & 70 & $42 \%$ since 1980 & $\begin{array}{c}\text { ANC }>20 \mu \mathrm{eq} 1^{-1} \text { at all } \\
\text { sites in } 2016\end{array}$ & Helliwell \& Kernan 2004 \\
\hline $\begin{array}{l}\text { Central Southern } \\
\text { Alps }\end{array}$ & 84 & High & 50 & 100 & $45 \%$ since 1980 & $\begin{array}{c}2 \%(40 \%) \text { of the lakes } \\
\text { with } A N C<0(<40) \\
\mu \text { eq } 1^{-1} \text { in } 2016\end{array}$ & Rogora 2004 \\
\hline Tatra Mountains & 31 & High & 60 & 65 & $\begin{array}{c}57 \% \text { since } 1985 \\
(35 \% \text { decrease of } \\
\mathrm{N} \text { dep.) }\end{array}$ & $\begin{array}{c}10 \% \text { of the lakes with } \\
\text { ANC }<0 \mu \text { eq } 1^{-1} \text { in } \\
2020\end{array}$ & Kopáček et al. 2004 \\
\hline
\end{tabular}

these regions since the $1980 \mathrm{~s}$, and additional recovery is predicted for the next decades. Predictions to 2016 indicate the potential for biological recovery and a return to 'good status' as required by the EU Water Framework Directive (Helliwell \& Kernan 2004). Nevertheless, the model simulations indicated that even the full implementation of the Gothenburg Protocol will not be sufficient to allow a complete recovery of mountain lakes in these acid-sensitive regions. The chemical characteristics of most of the sites will remain some way from simulated pre-acidification conditions.

If we assume an ANC limit of $20 \mu \mathrm{eq} \mathrm{l}^{-1}$ to indicate that the sites are capable of achieving the good ecological status required by the WFD, it is quite clear that some lakes in Norway, the Alps and the Tatras will not achieve ANC levels sufficient to support trout populations or acid-sensitive invertebrate species (Tab. 2).

The MAGIC simulations indicated that soils in lake catchments have acidified during the past 100 years and in many cases the base cation pools will not be fully replenished in the next decades. This is the main reason for the asymmetry observed in both Norway and the Alps between acidification and recovery patterns (Rogora 2004; Wright \& Cosby 2004).

One of the main factors driving recovery in the near future will probably be the condition of lake catchments with regard to N saturation (Rogora 2004; Camarero et al. 2004). Major uncertainties in the model predictions are related to the possible effects of climate change on weathering processes and $\mathrm{N}$ dynamics (Camarero et al. 2004; Helliwell \& Kernan 2004). While N saturation would necessarily exacerbate acidification processes, the effects of climate change are not easily predictable and could either delay or accelerate recovery. Perturbations of climate parameters in the model to assess the effects on water chemistry at calibrated sites, as described in Camarero et al. (2004), are useful tools for a better understanding of climate-related processes at the catchment scale. The inclusion of such processes in future modelling may help to improve the fit of measured data and the reliability of model forecasts.
Despite the present uncertainties in the model simulations, the results presented here and elsewhere (Jenkins et al. 2003) clearly demonstrate how additional measures such as stricter controls of air pollutants emissions will be required if satisfactory water quality is to be achieved, and to allow biological recovery in mountain lakes in the future.

\section{CONCLUSION}

The papers collected in this special issue of the Journal of Limnology on "Measured and modelled trends in European mountain lakes" summarize a combined effort of modelling, palaeolimnological inference and long term monitoring. This multidisciplinary approach was revealed to be an important tool for understanding and forecasting the effects of human activities on mountain lakes. Long term monitoring is essential for the achievement of accurate model calibration, while palaeolimnological data can validate model hindcast and provide reference conditions.

On the other hand, model establishment is necessary if the results are to be upscaled from individual sites to eco-regions, to evaluate the extent of the studied phenomena. It also makes it possible to forecast the behaviour of remote lakes, and to evaluate different scenarios of pollution reduction in order to select the most effective for the recovery of endangered ecosystems.

We strongly recommend that monitoring activity be continued, to evaluate the effects of climatic change and to follow the results of the protocols for emission reduction. Furthermore, the long-term monitoring protocols should include other parameters at the key-sites, such as organic pollutants and metals, which may be invaluable for an evaluation of their effect on mountain regions, and to calibrate and validate dispersion and deposition models.

\section{ACKNOWLEDGMENTS}

The research activity summarised in this paper was funded over the years by national and international institutions, including the European Union, through the 
following projects: "Quantification of the susceptibility of Alpine lakes to acidification" (contract No. EV4V0114), "AL:PE, Acidification of mountain Lakes: Palaeolimnology and Ecology" (contract No. STEP-CT900079-(SMA) and EV5V-CT92-0205), "MOLAR: MOuntain LAkes Research" (contract No. ENV4-CT950007), "EMERGE: European Mountain lakes Ecosystems: Regionalisation, diaGnostic and socio-economic Evaluation" (contract No. EVK1-CT-1999-0032) and RECOVER:2010 (contract No. EVK1-CT-1999-00018).

\section{REFERENCES}

Boggero, A., A. Barbieri, J. de Jong, A. Marchetto \& R. Mosello. 1998. Chemistry and critical loads of Alpine lakes in Canton Ticino (Southern Central Alps). Aquat. Sci., 60: 300-315.

Camarero, L. \& J. Catalan. 1993. Chemistry of bulk precipitation in the Central and Eastern Pyrenees (Northeast Spain). Atmos. Environ., 27A: 83-94.

Camarero, L., R.F. Wright, J. Catalan \& M. Ventura. 2004 Application of MAGIC to Lake Redó (Central Pyrenees): an assessment of the effects of possible climate driven changes in atmospheric precipitation, base cation deposition, and weathering rates on lake water chemistry. $J$. Limnol., 63(1): 123-132.

Cosby, B.J., G.M. Hornberger, R.F. Wright \& J.N. Galloway. 1986. Modelling the effects of acid deposition: Control of long term sulphate dynamics by soil sulphate adsorption. Water Res. Res., 22: 1283-1291.

Cosby, B.J., R.C. Ferrier, A. Jenkins \& R.F. Wright. 2001. Modelling the effects of acid deposition - fifteen years of MAGIC: refinements, adjustments and inclusion of nitrogen dynamics. Hydrol. Earth System Sci., 5: 499-517.

Curtis, C.J., A.Barbieri, L. Camarero, M. Gabathuler, J. Galas, K. Hanselmann, J. Kopáček, R. Mosello, N. Rose, E. Stuchlik, H. Thies, U. Nickus, M. Ventura \& R.F. Wright. 2002. Application of static critical load models for acidity to high mountain lakes in Europe. Wat. Air Soil Pollut. Focus, 2: 115-126.

Evans, C.D. \& D.T. Monteith. 2002. Natural and anthropogenic changes in the chemistry of six UK mountain lakes. Wat. Air Soil Pollut., 2: 33-46.

Ferrier, R.C., R.F. Wright \& A. Jenkins. 2003. Special Issue: predicting recovery of acidified freshwaters in Europe and Canada. Hydrol. Earth System Sci., 7: 618 pp.

Guilizzoni, P., A. Marchetto, A. Lami, N.G. Cameron, P.G. Appleby, N.L. Rose, Ø. A. Schnell, C.A. Belis, A. Giorgis \& L. Guzzi. 1996. The environmental history of a mountain lake (Lago Paione Superiore, Central Alps, Italy) for the last c. 100 years: a multidisciplinary, paleolimnological study. J. Paleolimnol., 15: 245-264.

Helliwell, R. \& M. Kernan. 2004. Modelling hydrochemical and ecological trends in acid sensitive surface waters in the Scottish uplands. J. Limnol., 63(1): 111-122.

Henriksen, A. \& M. Posch. 2001. Steady-state models for calculating critical loads of acidity for surface waters. Wat. Air Soil Pollut. Focus, 1: 375-398.

Henriksen, A., J. Kämäri, M. Posch, G. Lövblad, M. Fresenius \& A. Wilander. 1990. Critical loads to surface waters in Fennoscandia. Nordic Council of Ministers, Copenhagen. Environmental Report, 17: 43 pp.

Jenkins, A. \& J. Cullen. 2001. An assessment of the potential impact of the Gothenburg Protocol on surface water chemistry using the dynamic MAGIC model at acid sensitive sites in the UK. Hydrol. Earth System Sci., 5: 529541

Jenkins, A., R.C. Ferrier \& B.J. Cosby. 1997. A dynamic model for assessing the impact of coupled sulphur and ni- trogen deposition scenarios on surface water acidification. J. Hydrol., 197: 111-127.

Jenkins, A., R.C. Ferrier \& R.F. Wright. 2001. Special Issue: assessment of recovery of European surface waters from acidification 1970-2000. Hydrol. Earth System Sci., 5: 542 pp.

Jenkins, A., L. Camarero, B.J. Cosby, R. Ferrier, M. Forsius, R. Helliwell, J. Kopáček, V. Majer, F. Moldan, M. Posch, M. Rogora, W. Schöpp \& R. Wright. 2003. The recovery of European surface waters from acidification. Hydrol. Earth System Sci., 7: 447-455.

Johannessen, M., R. Mosello \& H. Barth (Eds). 1990. Acidification processes in remote mountain lakes. Proc. CEC, Pallanza, June 20-22, 1989, Air Pollution Research Report 20. Guyot, Brussels: $216 \mathrm{pp}$

Jones, V.J., R.J. Flower, P.G. Appleby, J. Natkanski, N. Richardson, B. Rippey, A.C. Stevenson \& R.W. Battarbee. 1993. Paleolimnological evidence for the acidification and atmospheric contamination of lochs in the Cairngorm and Lochnagar areas of Scotland. J. Ecol., 81: 3-24.

Kalchev, R., I. Botev, M. Hristozova, W. Naidenow, G. Raikova-Petrova, M. Stoyneva, D. Temniskova-Topalova \& T. Trichkova. 2004. Ecological relations and temporal changes in the pelagial of high mountain lakes in the Rila Mountains (Bulgaria). J. Limnol., 63(1): 90-100.

Kernan, M.R.S. \& J. Catalan. 2003. A typology for European mountain lakes. In. Ruoppa, M., P. Heinonen, A. Pilke, S. Rekolainen, H. Toivo \& H. Vuoristo (Eds). How to assess and monitor ecological quality in freshwaters. Tema Nord 2003:547, Nordic Council of Ministers, Copenhagen: 1218.

Kopáček, J., D. Hardekopf, V. Majer, P. Pšenáková, E. Stuchlík \& J. Veselý. 2004. Response of alpine lakes and soils to changes in acid deposition: the MAGIC model applied to Tatra Mountains' region (Central Europe). $J$. Limnol., 63(1): 143-156.

Lami, A., A. Marchetto, P. Guilizzoni, A. Giorgis \& J. Masaferro. 1994. Paleolimnological records of carotenoids and carbonaceous particles in sediments of some lakes in Southern Alps. Hydrobiologia, 274: 57-64.

Marchetto, A., P. Guilizzoni, A. Lami \& A. Giorgis. 1993. Diatom-based $\mathrm{pH}$ reconstruction in an Alpine lake: the importance of temperature changes. 5th International Conference on the Conservation and Management of Lakes. Stresa 17-21 May 1993. In: G. Giussani \& C. Callieri (Eds). Strategies for lake ecosystems beyond 2000. Proceedings: 423-426.

Marchetto, A., R. Mosello, M. Rogora, M. Manca, A. Boggero, G. Morabito, S. Musazzi, G.A. Tartari, A.M. Nocentini, A. Pugnetti, R. Bettinetti, P. Panzani, M. Armiraglio, P. Cammarano \& A. Lami. 2004. The chemical and biological response of two remote mountain lakes in the Southern Central Alps (Italy) to twenty years of changing physical and chemical climate. J. Limnol., 63(1): 77-89.

Mosello, R., A. Barbieri, G. Bendetta, A. Boggero, A. Marchetto, R. Psenner, D. Tait \& G.A. Tartari. 1993. Quantification of the susceptibility of alpine lakes to acidification. Mem. Ist. ital. Idrobiol., 52: 355-386.

Mosello, R., A. Lami, A. Marchetto, M. Rogora, B. Wathne, L. Lien, J. Catalan, L. Camarero, M. Ventura, R. Psenner, K. Koinig, H. Thies, S. Sommaruga-Wögrath, U. Nickus, D. Tait, B. Thaler, A. Barbieri \& R. Harriman. 2002. Trends in the water chemistry of high altitude lakes in Europe. Water Air Soil Pollut. Focus, 2: 75-89.

Patrick, S., R.W. Battarbee, B.M. Wathne \& R. Psenner. 1998. Measuring and modelling the dynamic response of remote mountain lake ecosystems to environmental change: An introduction to the MOLAR project. In: Kovar, U. Tappeiner, N.E. Peters \& R.G. Craig (Eds), Hydrology, water resources and ecology in headwaters. Proceedings of the HeadWater'98 Conference, Merano: 403-410. 
Posch, M., M. Forsius, J. Johansson, J. Vuorenmaa \& J. Kamari. 2003. Modeling the recovery of acid-sensitive Finnish headwater lakes under present emission reduction agreements. Hydrol. Earth Syst. Sci., 7: 484-493.

Psenner, R. \& R. Schmidt. 1992. Climate driven $\mathrm{pH}$ control of remote mountain lakes and effects on acid deposition. Nature, 356: 781-783.

Psenner, R., R. Mosello, A. Boggero, A. Marchetto, B. Wathne \& L. Lien. 2000. Mountain lake research (MOLAR): Atmospheric deposition and lake water chemistry. Verh. int. Ver. Limnol., 27: 1008-1011.

Rogora, M. 2004. Acidification and recovery at mountain lakes in Southern Central Alps assessed by the MAGIC model. J. Limnol., 63(1): 133-142.

Rose, N., E. Shilland, H. Yang, T. Berg, L. Camarero, R. Harriman, K. Koinig, L. Lien, U. Nickus, E. Stuchlkik, H. Ties \& M. Ventura. 2002. Deposition and storage of spheroidal carbonaceous fly-ash particles in European lake sediments and catchment soils. Water Air Soil Pollut. Focus, 2: 251-260.

Rose N.L., D.T. Monteith, H. Kettle, R. Thompson, H. Yang $\&$ D. Muir. 2004. A consideration of potential confounding factors limiting chemical and biological recovery at Lochnagar, a remote mountain loch in Scotland. $J$. Limnol., 63(1): 63-76.

Schöpp, W., M. Posch, S. Mylona \& M. Johansson. 2003. Long-term development of acid deposition (1880-2030) in sensitive freshwater regions in Europe. Hydrol. Earth Syst. Sci., 7: 436-446.

Skjelkvåle, B.L., J. Mannio, A.Wilander \& T. Andersen. 2001a. Recovery from acidification of lakes in Finland, Norway and Sweden. Hydrol. Earth Syst. Sci., 5: 273-541.

Skjelkvåle, B.L., J.L. Stoddard \& T. Andersen. 2001b. Trends in surface water acidification in Europe and North America (1989-1998). Water Air Soil Pollut., 130: 787-792.

Straškrabová, V., C. Callieri \& J. Fott (Eds). 1999. Pelagic food web in mountain lakes. MOuntain LAkes Research Program. J. Limnol., 58: 146 pp.
The MOLAR Water Chemistry Group. 1999. The MOLAR Project: atmospheric deposition and lake water chemistry. J. Limnol., 58(2): 88-106.

UN-ECE. 1999. Protocol to the 1979 Convention on Longrange Transboundary Air Pollution to abate acidification, eutrophication and ground-level ozone. United Nations, Economic Commission for Europe, Geneva, Switzerland: $63 \mathrm{pp}$.

Wathne, B.M., R. Mosello, A. Henriksen \& A. Marchetto. 1990. Comparison of the chemical characteristics of mountain lakes in Norway and Italy. Proc. EEC Workshop on "Acidification processes in remote mountain lakes", Pallanza, 20-22 June 1989, Air Pollution Research Report 20: 41-58.

Wathne, B.M. 1992. Acidification of mountain lakes: palaeolimnology and ecology. The AL:PE Project. In: Mosello, R., B.M. Wathne \& G. Giussani (Eds), Limnology on groups of remote lakes: ongoing and planned activities. Doc. Ist. ital. Idrobiol., 32:7-22.

Wathne, B.M., R.W. Battarbee, M. Johannessen, R. Mosello, S. Patrick, G.G. Raddum, B.O. Rosseland, L. Lien, D. Tait, J.-C. Massabuau \& G. Blake. 1993. The AL:PE projects, first results and further plans. Mem. Ist. ital. Idrobiol., 52: 341-354.

Wright, R.F., B.J. Cosby, R.C. Ferrier, A. Jenkins, A. Bulger \& R. Harriman. 1994. Changes in acidification of lochs in Galloway, southwestern Scotland, 1979-1988: The MAGIC model used to evaluate the role of afforestation, calculate critical loads and predict fish status. J. Hydrol., 161: 257-285.

Wright, R.F., B.A. Emmett \& A. Jenkins. 1998. Acid deposition, land-use change and global change: MAGIC7 model applied to Aber (NITREX project) and Risdalsheia (RAIN and CLIMEX projects). Hydrol. Earth Syst. Sci., 2: 385397.

Wright, R.F. \& B.J. Cosby. 2004. Recovery of acidified mountain lakes in Norway as predicted by the MAGIC model. J. Limnol., 63(1): 101-110. 